\title{
Meal Test for Glucose-Dependent Insulinotropic Peptide (GIP) in Obese and Type 2 Diabetic Patients
}

\author{
J. ŠKRHA ${ }^{1,2}$, J. HILGERTOVÁ ${ }^{2}$, M. JAROLÍMKOVÁ ${ }^{2}$, M. KUNEŠOVÁ ${ }^{3}$, M. HILL ${ }^{3}$ \\ ${ }^{1}$ Third Department of Internal Medicine and ${ }^{2}$ Laboratory for Endocrinology and Metabolism, First \\ Faculty of Medicine, Charles University in Prague, and ${ }^{3}$ Institute of Endocrinology, Prague, Czech \\ Republic
}

Received September 17, 2009

Accepted January 6, 2010

On-line April 20, 2010

\section{Summary}

Glucose-dependent insulinotropic peptide (GIP) contributes to incretin effect of insulin secretion which is impaired in Type 2 diabetes mellitus. The aim of this study was to introduce a simple meal test for evaluation of GIP secretion and action and to examine GIP changes in Type 2 diabetic patients. Seventeen Type 2 diabetic patients, 10 obese non-diabetic and 17 nonobese control persons have been examined before and after 30 , 60 and 90 min stimulation by meal test. Serum concentrations of insulin, C-peptide and GIP were estimated during the test. Impaired GIP secretion was found in Type 2 diabetic patients as compared with obese non-diabetic and non-obese control persons. The $\mathrm{AUC}_{\mathrm{GIP}}$ during 90 min of the meal stimulation was significantly lower in diabetic patients than in other two groups $(p<0.03)$. Insulin concentration at 30 min was lower in diabetic than in non-diabetic persons and the GIP action was delayed. The $\Delta \mathrm{IRI} / \Delta \mathrm{GIP}$ ratio increased during the test in diabetic patients, whereas it progressively decreased in obese and nonobese control persons. Simple meal test could demonstrate impaired GIP secretion and delayed insulin secretion in Type 2 diabetic patients as compared to obese non-diabetic and nonobese healthy control individuals.

\section{Key words}

Glucose-dependent insulinotropic peptide - Type 2 diabetes mellitus • Obese non-diabetic subjects $\bullet$ Insulin secretion

\section{Corresponding author}

Jan Škrha, $3^{\text {rd }}$ Department of Internal Medicine, $1^{\text {st }}$ Faculty of Medicine, Charles University, U Nemocnice 1, 12808 Prague 2, Czech Republic. E-mail: jan.skrha@lf1.cuni.cz

\section{Introduction}

Postprandial glucose concentration is controlled by insulin secretion regulated both directly by the absorbed nutrients and through the secretion of incretin hormones, namely glucagon-like peptide 1 (GLP-1) and glucose-dependent insulinotropic peptide (GIP) (Meier and Nauck 2005, Yamada et al. 2006). The incretin effect contributes to the postprandial insulin release by about $40-70 \%$ in healthy persons, whereas in type 2 diabetic patients this effect is markedly reduced (Holst 2008). The mechanisms underlying the loss of incretin effect have not been completely elucidated, although two defects have been suggested. First, a decreased GLP-1 availability in Type 2 diabetic patients has been described which may be caused either by defects in GLP-1 secretion or by increased inactivation through dipeptidyl peptidase IV (DPP IV) (Holst 2008, Nauck et al. 1986). This mechanism is supported by the clinical evidence that the administration of GLP-1 analogues as well as DPP IV inhibitors improves insulin secretion and contributes to better glucose control in Type 2 diabetic patients (Holst 2008). Second possible mechanism may arise from diminished insulinotropic action of GIP within the betacells. An impaired response to GIP in terms of insulin secretion in Type 2 diabetes was proposed by Nauck et al. (1993). The loss of GIP effect may be caused by defective expression of GIP receptors (Holst et al. 1997), downregulation of GIP signaling (Xu et al. 2007) or reduced beta-cell mass and function (Meier and Nauck 2004). GIP concentrations have been found to be normal, decreased or increased in Type 2 diabetic patients and 
Table 1. Characteristics of Type 2 diabetic patients, obese non-diabetic patients and non-obese control persons.

\begin{tabular}{llll}
\hline & $\begin{array}{l}\text { Control non-obese persons } \\
(\mathbf{n = 1 7 )}\end{array}$ & $\begin{array}{l}\text { Obese non-diabetic persons } \\
(\mathbf{n = 1 0 )}\end{array}$ & $\begin{array}{l}\text { Type 2 DM } \\
(\mathbf{n}=17)\end{array}$ \\
\hline Age (years) & $44(31-58)$ & $44(21-62)$ & $59(43-71)$ \\
BMI $\left(\mathrm{kg} / \mathrm{m}^{2}\right)$ & $23.1 \pm 3.1$ & $38.0 \pm 5.2^{\mathrm{b}}$ & $29.5 \pm 4.5^{\mathrm{ax}}$ \\
HOMA index & $3.93 \pm 1.52$ & $6.81 \pm 2.0^{\mathrm{b}}$ & $12.75 \pm 8.37^{\mathrm{cy}}$ \\
Cholesterol (mmol/l) & $4.72 \pm 1.54$ & $4.77 \pm 1.34$ & $4.81 \pm 0.83$ \\
HDL-cholesterol (mmol/l) & $1.56 \pm 0.4$ & $1.41 \pm 0.41$ & $1.25 \pm 0.35^{\mathrm{b}}$ \\
LDL-cholesterol (mmol/l) & $3.04 \pm 0.67$ & $2.98 \pm 0.72$ & $2.79 \pm 0.70$ \\
Triglycerides (mmol/l) & $1.00 \pm 0.41$ & $1.58 \pm 0.93^{\mathrm{a}}$ & $1.95 \pm 1.29^{\mathrm{c}}$ \\
\hline
\end{tabular}

Results are expressed as mean \pm SD or means with 2SD range. Statistical significance as compared to control group: ${ }^{a} p<0.01$, ${ }^{b} p<0.001$ and to obese non-diabetic persons: ${ }^{x} p<0.05,{ }^{y} p<0.01$

impaired GIP secretion is therefore unlikely (Knop et al. 2007a). In addition, it was not elucidated if diminished incretin effects could be a primary cause, potentially contributing to the development of Type 2 diabetes or if they would develop secondarily as a consequence of metabolic and hormonal disturbances in diabetes development. However, recent studies suggest that the incretin effects are diminished secondarily in the course of Type 2 diabetes (Knop et al. 2007b).

In addition to incretin effect, recent data indicate that GIP exerts the effects on adipose tissue and lipid metabolism to promote fat deposition and insulin resistance (Yamada et al. 2006). GIP receptors have been demonstrated on adipocytes and anabolic effects of GIP involving stimulation of glucose uptake, fatty acid synthesis and fatty acid incorporation into adipose tissue have been described (Yip et al. 1998). Fat ingestion increases GIP secretion from intestinal K-cells followed by their hyperplasia. Recent data confirm that GIP plays an important role in the pathogenesis of obesity and that GIP receptor blockade may protect from diet-induced obesity (Miyawaki et al. 2002).

The evaluation of GIP action may be clinically important. In the present study we developed simple mixed-meal test for screening of GIP changes in obese and Type 2 diabetic patients.

\section{Patients and Methods}

A total of 17 Type 2 diabetic patients, 10 obese non-diabetic persons and 17 non-obese healthy controls participated in this study. Subject characteristics are presented in Table 1. Normal glucose tolerance in obese non-diabetic persons was confirmed by oral glucose tolerance test. All persons had normal liver enzymes and serum creatinine concentration. Diabetic patients had proven diabetes for at least two years and were treated by metformin only. In a mixed meal challenge, breakfast composed from $200 \mathrm{ml}$ Resource drink (Nestle, Prague) containing $28 \mathrm{~g}$ saccharides, $7 \mathrm{~g}$ fats and $18.8 \mathrm{~g}$ protein with one roll $(50 \mathrm{~g})$ and $10 \mathrm{~g}$ butter. The total caloric content of this standard testing breakfast was $445 \mathrm{kcal}$ $(1850 \mathrm{~kJ})$. All examined persons gave their written consent and the study was approved by local Ethics Committee of the University Hospital.

Blood samples for biochemical analyses were drawn in the fasting state and then after 30,60 and 90 min of the test. Glucose concentrations were measured in capillary blood samples using glucose oxidase method on glucose analyzer Super GLAmbulance (Dr. Müller Gerätebau, Freital, Germany), glycated hemoglobin $\mathrm{HbA}_{1} \mathrm{c}$ by Imx GHb Assay System on Abbott Analyzer (Abbott, Chicago, USA) and expressed according to IFCC standards (normal values are 2.8-4.0\%). Serum total cholesterol, HDL- and LDL-cholesterol, triglycerides, urea, creatinine, uric acid and total protein concentrations were estimated in the central laboratory by routine methods on Hitachi analyzer. Serum insulin concentrations (IRI) were measured by radioimmunoassay kits (CIS Bio International, Gif-Sur-Yvette Cedex, France) with normal values in the range of $9-24 \mathrm{mU} / \mathrm{l}$ in our laboratory. The cross-reactivity with proinsulin declared by the manufacturer was below $14 \%$. C-peptide concentrations were determined by radioimmunoassay kits (Immunotech, Czech Republic). Total GIP concentration was measured by radioimmunoassay kit (Phoenix Pharmaceuticals Inc., USA). AUC $\mathrm{AIP}_{\mathrm{GP}}$ for 0-90 min was estimated in all patients. Differences in the 
Table 2. Biochemical results from the standard meal stimulation.

\begin{tabular}{|c|c|c|c|}
\hline & $\begin{array}{l}\text { Control non-obese persons } \\
(n=17)\end{array}$ & $\begin{array}{l}\text { Obese non-diabetic persons } \\
(n=10)\end{array}$ & $\begin{array}{l}\text { Type } 2 \text { DM } \\
(n=17)\end{array}$ \\
\hline \multicolumn{4}{|c|}{ Glucose (mmol/l) } \\
\hline $0 \mathrm{~min}$ & $5.1 \pm 0.2$ & $5.6 \pm 0.2$ & $8.9 \pm 0.6^{\mathrm{cz}}$ \\
\hline $30 \mathrm{~min}$ & $6.5 \pm 0.3$ & $6.9 \pm 0.2$ & $11.3 \pm 0.7^{\mathrm{cz}}$ \\
\hline $60 \min$ & $5.7 \pm 0.3$ & $5.5 \pm 0.2$ & $13.2 \pm 0.8^{\mathrm{cz}}$ \\
\hline $90 \min$ & $5.6 \pm 0.2$ & $5.5 \pm 0.2$ & $13.0 \pm 0.9^{c z}$ \\
\hline \multicolumn{4}{|c|}{ Insulin (mU/l) } \\
\hline $0 \mathrm{~min}$ & $17.3 \pm 1.4$ & $27.5 \pm 2.7^{\mathrm{c}}$ & $30.7 \pm 4.0^{\mathrm{c}}$ \\
\hline $30 \min$ & $80.0 \pm 13.4$ & $151.9 \pm 29.0^{\mathrm{a}}$ & $67.4 \pm 10.0^{z}$ \\
\hline $60 \min$ & $58.6 \pm 11.2$ & $94.6 \pm 10.4^{\mathrm{b}}$ & $87.8 \pm 14.0^{\mathrm{a}}$ \\
\hline $90 \min$ & $49.1 \pm 9.0$ & $71.4 \pm 8.0^{\mathrm{a}}$ & $92.7 \pm 14.0^{\mathrm{c}}$ \\
\hline \multicolumn{4}{|c|}{ IRI/Glucose } \\
\hline $0 \mathrm{~min}$ & $3.45 \pm 0.30$ & $6.67 \pm 1.50^{\mathrm{b}}$ & $3.48 \pm 0.40^{\mathrm{y}}$ \\
\hline $30 \mathrm{~min}$ & $12.07 \pm 1.76$ & $23.7 \pm 4.10^{\mathrm{b}}$ & $6.05 \pm 1.20^{\mathrm{cz}}$ \\
\hline $60 \min$ & $9.90 \pm 1.36$ & $22.2 \pm 5.28^{b}$ & $6.74 \pm 1.10^{\mathrm{az}}$ \\
\hline $90 \min$ & $8.60 \pm 1.41$ & $16.6 \pm 3.90^{\mathrm{a}}$ & $7.67 \pm 1.11^{\mathrm{z}}$ \\
\hline \multicolumn{4}{|c|}{ C-peptide (nmol/l) } \\
\hline $0 \mathrm{~min}$ & $0.55 \pm 0.05$ & $1.37 \pm 0.19^{c}$ & $0.94 \pm 0.09^{\mathrm{cx}}$ \\
\hline $30 \min$ & $1.57 \pm 0.11$ & $2.83 \pm 0.28^{\mathrm{c}}$ & $1.43 \pm 0.13^{\mathrm{z}}$ \\
\hline $60 \min$ & $1.36 \pm 0.12$ & $2.68 \pm 0.13^{\mathrm{c}}$ & $1.80 \pm 0.18^{\mathrm{az}}$ \\
\hline $90 \min$ & $1.34 \pm 0.11$ & $2.48 \pm 0.16^{\mathrm{c}}$ & $1.91 \pm 0.19^{\text {by }}$ \\
\hline \multicolumn{4}{|c|}{ GIP $(\mathrm{pmol} / \mathrm{l})$} \\
\hline $0 \mathrm{~min}$ & $49 \pm 9$ & $42 \pm 5$ & $44 \pm 7$ \\
\hline $30 \mathrm{~min}$ & $259 \pm 49$ & $251 \pm 20$ & $170 \pm 15^{\mathrm{az}}$ \\
\hline $60 \mathrm{~min}$ & $207 \pm 19$ & $220 \pm 26$ & $180 \pm 14^{\mathrm{ax}}$ \\
\hline $90 \min$ & $195 \pm 19$ & $292 \pm 30^{\mathrm{b}}$ & $163 \pm 15^{\mathrm{az}}$ \\
\hline \multicolumn{4}{|c|}{$I R I / G I P$} \\
\hline $0 \mathrm{~min}$ & $0.54 \pm 0.09$ & $0.72 \pm 0.08$ & $0.83 \pm 0.10^{\mathrm{b}}$ \\
\hline $30 \mathrm{~min}$ & $0.48 \pm 0.10$ & $0.63 \pm 0.12$ & $0.39 \pm 0.05^{\mathrm{x}}$ \\
\hline $60 \mathrm{~min}$ & $0.30 \pm 0.04$ & $0.47 \pm 0.08$ & $0.50 \pm 0.07^{\mathrm{b}}$ \\
\hline $90 \min$ & $0.26 \pm 0.04$ & $0.27 \pm 0.04$ & $0.81 \pm 0.28^{\text {by }}$ \\
\hline
\end{tabular}

The results are expressed as means \pm SEM. Statistical significance compared to control non-obese persons: ${ }^{a} p<0.05,{ }^{b} p<0.01$, ${ }^{c} p<0.005$, and to obese non-diabetic subjects: ${ }^{x} p<0.05,{ }^{y} p<0.01,{ }^{z} p<0.005$

IRI $(\Delta \mathrm{IRI})$ and GIP $(\Delta \mathrm{GIP})$ concentrations at 30,60 and $90 \mathrm{~min}$ related to basal values were used for comparison of dynamic hormone changes during the meal test. The $\Delta \mathrm{IRI} / \Delta \mathrm{GIP}$ ratio expressing the insulin concentration change related to corresponding GIP change was calculated.

The insulin sensitivity in all individual persons was expressed by the Homeostasis Model Assessment (HOMA) index calculated from basal plasma glucose $\left(\mathrm{G}_{0}\right)$ and insulin $\left(\mathrm{I}_{0}\right)$ concentrations using the formula: $\left(\mathrm{G}_{0} \times \mathrm{I}_{0}\right) / 22.5$ (Matthews et al. 1985).
The results were expressed as mean \pm SEM. Repeated measures ANOVA model followed by Bonferroni multiple comparisons was used for evaluation of the relationships between hormone levels and factors. The ANOVA model consisted of betweensubject factor status (diabetes, obese, controls), subject factor (extracting the inter-individual variability), within-subject factor time of the trial and status $\times$ time interaction. The original data was transformed by a power transformation prior ANOVA testing to attain Gaussian data distribution and homoscedasticity. 
Pearson's correlation assessing the relationship between GIP or IRI/GIP index and diabetes duration, BMI, HbA1c or HOMA index was calculated.

\section{Results}

The results of biochemical variables in diabetic, obese and non-obese control subjects are shown in Table 2 and Figure 1. Diabetes control was assessed in diabetic patients by $\mathrm{HbAlc}$ which was significantly higher than in control non-obese persons $(6.1 \pm 1.4 \%$ vs. $3.6 \pm 0.4 \%, \mathrm{p}<0.001)$. Basal and postmeal hyperinsulinemia in obese non-diabetic subjects sustained normal glucose tolerance. This contrasted with delayed answer in the insulin secretion of Type 2 diabetic patients as compared to both obese and non-obese control persons (Fig. 1a). Similar picture of delayed insulin secretion in Type 2 diabetes was also obtained when insulin was related to glucose (Table 2). Serum insulin related to plasma glucose concentration in 30 and $60 \mathrm{~min}$ of the test was significantly lower in diabetic patients than in nonobese and obese non-diabetic subjects (Table 2). Basal GIP concentrations were comparable in all three groups. However, changes in GIP concentrations ( $\Delta \mathrm{GIP})$ demonstrated diminished secretion in the first $30 \mathrm{~min}$ in Type 2 diabetic patients as compared with obese and nonobese control subjects (Fig. 1b) and area under the curve $\mathrm{AUC}_{\mathrm{GIP}}$ in 0-90 min was significantly smaler in diabetic patients than in non-diabetic subjects (13.6 \pm 3.8 vs. $17.5 \pm 6.5, \mathrm{p}<0.03)$. The dynamic changes in $\Delta \mathrm{IRI} / \Delta \mathrm{GIP}$ ratio were different in diabetic than in non-obese or obese control persons (Fig. 1c). Progressive decrease of this ratio in obese and non-obese control persons contrasted with increasing ratio observed in Type 2 diabetic patients during the test.

Positive relationship was found between diabetes duration and both GIP concentrations at 60 and $90 \mathrm{~min}$ $(\mathrm{r}=0.47$ and $\mathrm{r}=0.49, \mathrm{p}<0.05)$ and GIP increments $(\Delta \mathrm{GIP}) \quad(\mathrm{r}=0.41$ and $\mathrm{r}=0.42, \mathrm{p}<0.05)$ whereas no significant relationship was observed at basal state and at $30 \mathrm{~min}$ of the test. Diabetes duration was inversely related to IRI/GIP ratio at 60 and $90 \mathrm{~min}$ of the test $(\mathrm{r}=-0.35$ and $\mathrm{r}=-0.42, \mathrm{p}<0.05)$. No significant effect of insulin resistance expressed by HOMA index on GIP secretion was observed in any of the groups.

We could not prove any relationship between diabetes control assessed by HbAlc and GIP concentration or other variables.
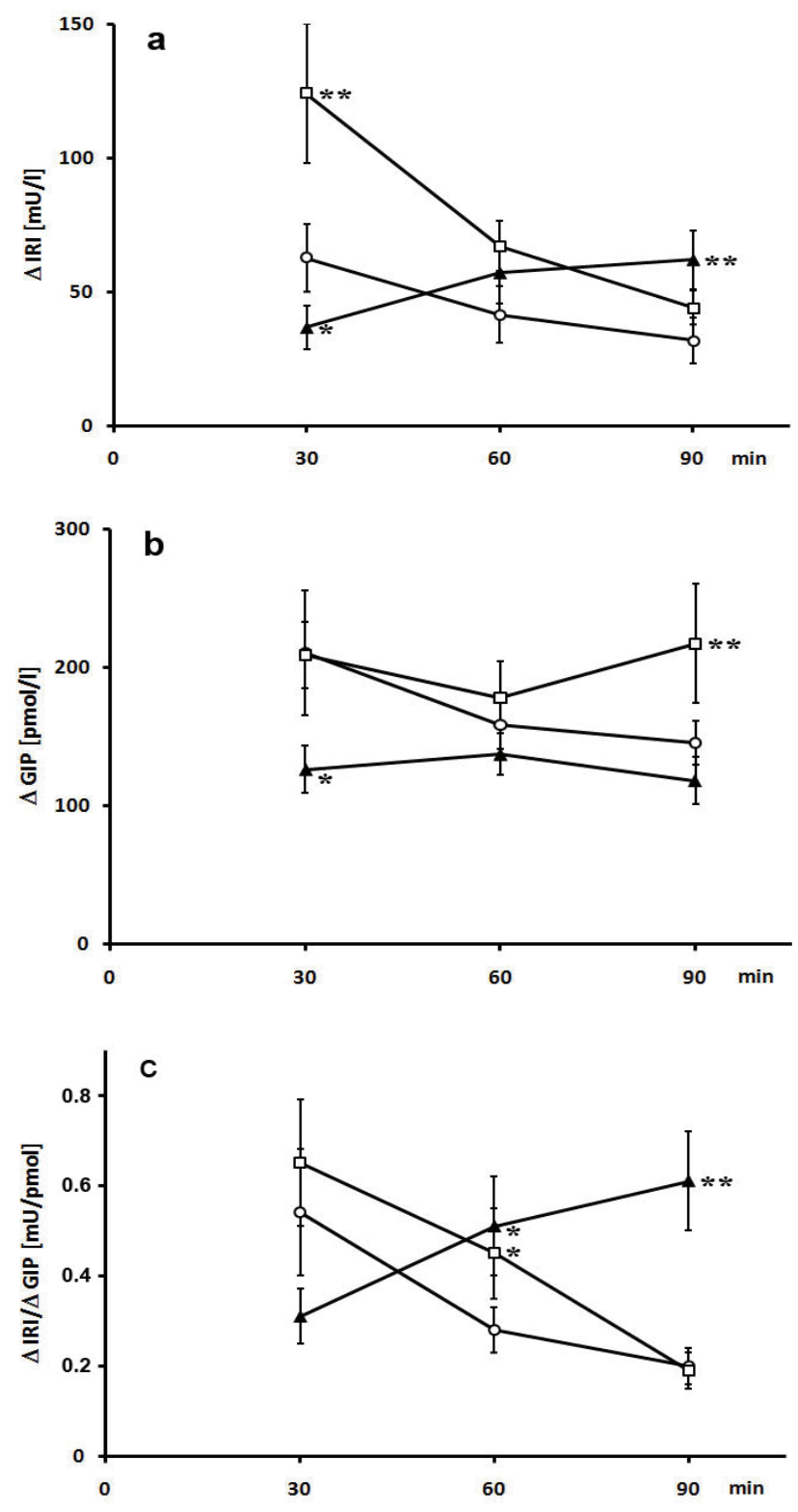

Fig. 1. Increment in serum insulin concentration ( $\Delta I R I)(a)$, plasma GIP concentration ( $\Delta$ GIP) (b), and ratios between increment of insulin and GIP concentrations ( $\Delta$ IRI/ $\Delta$ GIP) (c) related to basal values. Time course of variables in Type 2 diabetic patients (triangles) and obese persons (squares) are compared with controls persons (circles). Statistical significance compared to non-obese controls: ${ }^{*} p<0.01,{ }^{* *} p<0.001$

\section{Discussion}

In the present study we developed simple meal test which may prove the changes in GIP secretion and action under different conditions. In comparison with usually used oral glucose tolerance test (oGTT) this meal test is more physiological as it contains all main nutrients.

We found no difference between basal plasma GIP concentration in diabetic and obese persons as 
compared to control persons. The changes of serum GIP concentrations in diabetic patients were comparable with those in obese and non-obese control persons, although the GIP concentration at 30 min was significantly lower in patients with diabetes. This caused lower increment of GIP concentration supposing lower acute GIP secretion stimulated by the mixed meal in diabetic patients.

In addition, the GIP area under the curve $\left(\mathrm{AUC}_{\mathrm{GIP}}\right)$ in diabetic patients was significantly smaller than in non-obese and obese non-diabetic persons. These results demonstrate that impaired GIP secretion may be present in Type 2 diabetic patients. This observation is in agreement with other reports (Toft-Nielsen et al. 2001), whereas significant increase of GIP stimulation in Type 2 diabetes was reported previously (Vollmer et al. 2008, Ross et al. 1977, Jones et al. 1989). We could not identify any factors influencing the lower GIP secretion in our diabetic patients.

Delayed insulin secretion was observed in Type 2 diabetics in comparison with non-diabetic control persons. We found that both IRI/GIP and $\Delta \mathrm{IRI} / \Delta \mathrm{GIP}$ ratios during the test have similar changes in control nonobese and obese persons but they were different in Type 2 diabetic patients. The $\Delta \mathrm{IRI} / \Delta \mathrm{GIP}$ ratio progressively decreased in subjects without diabetes, whereas it increased in diabetic patients during $90 \mathrm{~min}$ after meal stimulation. It may be interpreted that betacells in Type 2 diabetes are insensitive to meal and to the stimulation by incretin hormone GIP in the acute phase (in the first $30 \mathrm{~min}$ after meal stimulation). This is also supported by the strong association with delayed insulin secretion. Impaired GIP stimulation of the beta-cell, lacking GLP-1 effect and continual blood glucose increase may cause the observed abnormal course of IRI/GIP and $\Delta \mathrm{IRI} / \Delta \mathrm{GIP}$ ratios during the test.

Reduced incretin effect in Type 2 diabetes with impaired insulin secretion was described earlier (Nauck et al. 1986, Nauck et al. 1993) and defective GIP receptor expression has been suggested (Holst et al. 1997, Xu et al. 2007). Down-regulation of pancreatic GIP receptors causing impaired beta-cell sensitivity to GIP was found in diabetic and obese rats compared to non-obese controls (Younan and Rashed 2007). The improved diabetes control in diabetic rats was associated with restored GIP sensitivity and chronic hyperglycemia was therefore regarded as a cause of down-regulated GIP receptors (Piteau et al. 2007). Similar improvement of insulin response to GLP-1 and GIP was found in Type 2 diabetic patients following four weeks of near normalization of blood glucose (Hojberg et al. 2009). In our study we could not find any relationship between diabetes control and plasma GIP concentrations as well as IRI/GIP or $\Delta \mathrm{IRI} / \Delta \mathrm{GIP}$ ratios. The impaired GIP effect increases with deterioration of glucose tolerance as demonstrated in patients with secondary diabetes due to chronic pancreatitis (Knop et al. 2007b). It further stresses that the incretin defect is more probably secondary in the course of Type 2 diabetes (Knop et al. 2007a). The elimination rate of GIP is similar in diabetic and healthy subjects and differences in dipeptidylpeptidase IV activities do not seem to contribute to the defective GIP insulinotropic effect in Type 2 diabetes (Vilsboll et al. 2006).

We could not demonstrate any relationship between insulin resistance expressed by HOMA index and stimulated GIP concentrations. Our higher HOMA index in control persons was explained by higher values of normal serum insulin concentration in our laboratory. Changes in glucose concentration during the test meal were not associated with GIP concentrations in diabetic and non-diabetic persons. We observed that longer diabetes duration was associated with decreased insulin release.

This study has some limitations. Firstly, short test of 90 min duration was used for the examination. The extension to 120 and 180 min would offer better data on GIP or insulin changes. However, we did not follow longer test because a shorter period can be more reliable for clinical practice. Ninety minutes were sufficient to demonstrate a difference between diabetic and non-diabetic subjects including obese individuals. Secondly, we could not differentiate between GIP and GLP-1 effects on betacell insulin secretion because only GIP concentrations were measured, whereas GLP-1 was not assessed. We cannot therefore conclude which factors may participate in delayed insulin secretion in Type 2 diabetic patients, although it has been supposed that both incretin changes are rather a consequence of diabetes than a cause of the disease. Thirdly, small samples of examined persons have been used in the present pilot study and therefore statistical significance of observed differences may be lower. Finally, we used significantly more obese non-diabetic than diabetic persons. However, we could not demonstrate any difference between non-obese and obese persons with normal glucose tolerance in GIP secretion.

In conclusion, our results of simple mixed meal test with physiological GIP stimulation proved impaired GIP secretion and delayed insulin secretion in Type 2 diabetic patients. No such effects were found in obese 
non-diabetic persons. Further studies elucidating the role of improved chronic diabetes control on reversibility of GIP secretion will be necessary.

\section{Conflict of Interest}

There is no conflict of interest.

\section{Acknowledgements}

The authors thank to Jana Pacnerová for technical assistance. This study was supported by research project MSM0021620807.

\section{References}

HOJBERG PV, VILSBOLL T, RABOL R, KNOP FK, BACHE M, KRARUP T, HOLST JJ, MADSBAD S: Four weeks of near-normalisation of blood glucose improves the insulin response to glucagons-like peptide-1 and glucose-dependent insulinotropic polypeptide in patients with type 2 diabetes. Diabetologia 52: 199-207, 2009.

HOLST JJ: The physiology and pharmacology of incretins in type 2 diabetes mellitus. Diabetes Obes Metab 10: 14-21, 2008.

HOLST JJ, GROMADA J, NAUCK MA: The pathogenesis of NIDDM involves a defective expression of the GIP receptor. Diabetologia 40: 984-986, 1997.

JONES IR, OWENS DR, LUZIO S, WILLIAMS S, HAYES TM: The glucose dependent insulinotropic polypeptide response to oral glucose and mixed meals is increased in patients with type 2 (non-insulin-dependent) diabetes mellitus. Diabetologia 32: 668-677, 1989.

KNOP FK, VILSBOLL T, HOJBERG PV, LARSEN S, MADSBAD S, VØLUND A, HOLST JJ, KRARUP T: Reduced incretin effect in type 2 diabetes: cause or consequence of the diabetic state? Diabetes 56: 1951-1959, 2007a.

KNOP FK, VILSBOLL T, HOJBERG PV, LARSEN S, MADSBAD S, HOLLST JJ, KRARUP T: The insulinotropic effect of GIP is impaired in patients with chronic pancreatitis and secondary diabetes mellitus as compared to patients with chronic pancreatitis and normal glucose tolerance. Regul Pept 144: 123-130, 2007b.

MATTHEWS DR, HOSKER JP, RUDENSKI AS, NAYLOR BA, TREACHER DF, TURNER RC: Homeostasis model assessment: insulin resistance and $\beta$-cell function from fasting plasma glucose and insulin concentrations in man. Diabetologia 28: 412-419, 1985.

MIYAWAKI K, YAMADA Y, BAN N, IHARA Y, TSUKIYAMA K, ZHOU H, FUJIMOTO S, OKU A, TSUDA K, TOYOKUNI S, HIAI H, MIZUNOYA W, FUSHIKI T, HOLST JJ, MAKINO M, TASHITA A, KOBARA Y, TSUBAMOTO Y, JINNOUCHI T, JOMORI T, SEINO Y: Inhibition of gastric inhibitory polypeptide signaling prevents obesity. Nat Med 8: 738-742, 2002.

MEIER JJ, NAUCK MA: Glucose-dependent insulinotropic popyleptide/gastric inhibitory polypeptide. Best Pract Res Clin Endocrinol Metab 18: 587-606, 2004.

MEIER JJ, NAUCK MA: Glucagon-like peptide 1 (GLP 1) in biology and pathology. Diabete Metab Res Rev 21: 91$117,2005$.

NAUCK MA, STÖCKMANN F, EBERT R, CREUTZFELDT W: Reduced incretin effect in type 2 (non-insulin dependent) diabetes. Diabetologia 29: 46-54, 1986.

NAUCK MA, HEIMESAAT MM, ORSKOV C, HOLST JJ, EBERT R, CREUTZFELDT W: Preserved incretin activity of glucagon-like peptide 1 [7-36 amide] but not of synthetic human gastric inhibitory polypeptide in patients with type-2 diabetes mellitus. J Clin Invest 91: 301-307, 1993.

PITEAU S, OLVER A, KIM SJ, WINTER K, POSPISILIK JA, LYNN F, MANHART S, DEMUTH HU, SPECK M, PEDERSON RA, MCINTOSH CHS: Reversal of islet GIP receptor down-regulation and resistance to GIP by reducing hyperglycemia in the Zucker rat. Biochem Biophys Res Commun 362: 1007-1012, 2007.

ROSS SA, BROWN JC, DUPRÉ J: Hypersecretion of gastric inhibitory polypeptide following oral glucose in diabetes mellitus. Diabetes 26: 525-529, 1977.

TOFT-NIELSEN MB, DAMHOLT MB, MADSBAD S, HILSTED LM, HUGHES TE, MICHELSEN BK, HOLST JJ: Determinants of impaired secretion of glucagons-like peptide-1 in type 2 diabetic patients. $J$ Clin Endocrinol Metab 86: 3717-3723, 2001. 
VILSBOLL T, AGERSO H, LAURITSEN T, DEACON CF, AABOE K, MADSBAD S, KRARUP T, HOLLST JJ: The elimination rates of intact GIP as well as its primary metabolite, GIP 3-42, are similar in type 2 diabetic patients and healthy subjects. Regul Pept 137: 168-172, 2006.

VOLLMER K, HOLST JJ, BALLER B, ELLRICHMANN M, NAUCK MA, SCHMIDT WE, MEIER JJ: Predictors of incretin concentrations in subjects with normal, impaired, and diabetic glucose tolerance. Diabetes 57: 678687, 2008.

XU G, KANETO H, LAYBUTT DR, DUVIVIER-KALI VF, TRIVEDI N, SUZUMA K, KING GL, WEIR GC, BONNER-WEIR S: Downregulation of GLP-1 and GIP receptor expression hy hyperglycemia. Possible contribution to impaired incretin effects in diabetes. Diabetes 56: 1551-1558, 2007.

YAMADA Y, MIYAWAKI K, TSUKIYAMA K, HARADA N, YAMADA CH, SEINO Y: Pancreatic and extrapancreatic effects of gastric inhibitory polypeptide. Diabetes 55 (Suppl 2): S86-S91, 2006.

YIP RG, BOYLAN MO, KIEFFER TJ, WOLFE MM: Functional GIP receptors are present on adipocytes. Endocrinology 139: 4004-4007, 1998.

YOUNAN M, RASHED A: Impairment of the insulinotropic effect of gastric inhibitory polypeptide (GIP) in obese and diabetic rats is related to the down-regulation of its pancreatic receptors. Gen Physiol Biophys 26: 181-193, 2007. 